\title{
Lectotipificaciones en Amaranthaceae de la Flora Argentina
}

\author{
NÉSTOR D. BAYÓN ${ }^{1, *}$ y DANIEL A. GIULIANO1
}

\begin{abstract}
Summary: Lectotypifications in Amaranthaceae for Flora Argentina. Lectotypes are designated for 36 species and 22 infraspecific taxa of Amaranthaceae for Flora Argentina which belong to the currently accepted genera Alternanthera, Blutaparon, Chamissoa, Froelichia, Hebanthe, and Pfaffia. Of all the lectotypifications, 20 are second step lectotypifications.
\end{abstract}

Key words: Alternanthera, Amaranthaceae, Blutaparon, Chamissoa, Froelichia, Hebanthe, nomenclature, Pfaffia.

\begin{abstract}
Resumen: Se designan lectotipos para 36 nombres específicos y 22 nombres infraespecíficos correspondientes a la familia Amaranthaceae de la Flora Argentina, los que pertenecen a los géneros actualmente aceptados Alternanthera, Blutaparon, Chamissoa, Froelichia, Hebanthe y Pfaffia. Del total, 20 corresponden a lectotipificaciones de segundo paso.
\end{abstract}

Palabras clave: Alternanthera, Amaranthaceae, Blutaparon, Chamissoa, Froelichia, Hebanthe, nomenclatura, Pfaffia.

\section{INTRODUCCIÓN}

La familia Amaranthaceae Juss. s.str. cuenta con 13 géneros y 97 especies en la flora argentina (Borsch, 2008), especialmente distribuidas en regiones subtropicales y templadas del territorio. En el marco del tratamiento de dicha familia para la Flora Argentina se designan lectotipos de nombres de especies y taxones infraespecíficos pertenecientes a los géneros actualmente aceptados Alternanthera Forssk., Blutaparon Raf., Chamissoa Kunth, Froelichia Moench., Hebanthe Mart. y Pfaffia Mart.

\section{Materiales y Métodos}

Se examinaron los protólogos de todos los nombres tipificados y se estudiaron ejemplares e imágenes digitales de los ejemplares del material original

\footnotetext{
${ }^{1}$ Área de Botánica, Departamento de Ciencias Biológicas, Facultad de Ciencias Agrarias y Forestales, Universidad Nacional de La Plata, Avda. 60 y 119, (1900) La Plata, Argentina.

*E-mail: nbayon@agro.unlp.edu.ar
}

disponibles en JSTOR (https://plants.jstor.org/), a través de los sitios web de los herbarios citados, o mediante imágenes enviadas por los curadores de las correspondientes instituciones. A continuación de las siglas de los herbarios se indica el código de barras del pliego donde se halla montado cada ejemplar; en el caso de que este no esté disponible se consigna el número de herbario precedido de la abreviatura " $n^{0}$ ". Los herbarios consultados fueron: AK, B, BAA, BAB, BAF, BM, BR, C, CAS, CORD, E, F, FR, G, G-DC, GB, GH, GOET, HAL, JE, K, KIP, LE, LIL, LINN, LP, M, MG, MO, MPU, NDG, NY, P, PH, PRE, S, SI, UC, US, TCD, TEX y W (Thiers, 2018). Cuando se emplea el término "espécimen" se considera como sinónimo de ejemplar según está definido en el Art. 8.2 de la versión en español del Código de Melbourne (Greuter \& Rankin Rodríguez, 2012), para evitar repeticiones de este último término en un mismo párrafo.

\section{Resultados}

Los nombres tratados se colocan bajo los respectivos nombres actualmente aceptados que se presentan en orden alfabético. 
1. Alternanthera albida (Moq.) Griseb., $A b h$. Königl. Ges. Wiss. Göttingen 19: 84. 1874. 三 Telanthera albida Moq., Prodr. [De Candolle] 13(2): 367. 1849. Tipo: Argentina. Buenos Aires, sin colector, s.n. (Lectotipo, aquí designado, K 000583047 [foto]!; isolectotipo, P 000622521 [foto]! [fragmento]).

= Alternanthera tomentella Seub., Fl. Bras. 5(1): 186. 1875. Tipo: Argentina. Córdoba, Córdoba capital, en las cercanías de la ciudad, 1-V-1871, P. G. Lorentz s.n. (Lectotipo, aquí designado, CORD 00002453 [Hoja A]!, CORD 00002454 [Hoja B]!).

= Alternanthera albida (Moq.) Griseb. f. globifera Suess., Repert. Spec. Nov. Regni Veg. 35: 299. 1934. Tipo: Argentina. Córdoba, Estancia Germania prope Córdoba, VI/XII-1874, P. G. Lorentz 118 (Lectotipo, aquí designado, M 0241587 [foto]!; isolectotipos, BM 000993123 [foto]!, F V0047572F [foto]!, G 00236902 [foto]!, MPU 016077 [foto]!).

= Alternanthera albida (Moq.) Griseb. f. amentacea Suess., Repert. Spec. Nov. Regni Veg. 35: 299. 1934. Tipo: Argentina. Córdoba, V-1871, P. G. Lorentz 393 (Lectotipo, aquí designado, K 000583046 [foto]!; isolectotipo, F V0047571F [foto]! [fragmento]).

En el protólogo de Telanthera albida Moq. el autor menciona una colección cerca de Buenos Aires sin citar su colector, si bien consigna "v.s. in h. Hook.". Se han localizado dos ejemplares que se ajustan a esta cita: uno en $\mathrm{K}$ el cual es designado como lectotipo de la especie por presentar numerosas ramas floríferas, mientras que el ejemplar de $\mathrm{P}$ consta de dos fragmentos.

En el protólogo de Alternanthera tomentella Seub. el autor menciona un ejemplar coleccionado por Lorentz cerca de Córdoba, consignando "v.s. in Herbar. Eichler". Los materiales tipo de las especies sudamericanas colectadas por Eichler están depositados en B (Stafleu \& Cowan, 1976); en este caso, el ejemplar se halla destruido (R. Vogt, curador de B, com. pers.). En consecuencia, se designa como lectotipo al ejemplar depositado en CORD, el cual coincide con la localidad consignada en el protólogo; este espécimen se halla montado sobre dos pliegos que presentan anotaciones cruzadas ("Hoja A" y "Hoja B"), por lo que deben ser consideradas como pertenecientes a un mismo ejemplar (Art. 8.3 del ICN; Turland et al., 2018), independientemente del hecho de que a cada pliego le fuera asignado un diferente número de código de barras.

En el protólogo de Alternanthera albida (Moq.) Griseb. f. globifera Suess. el autor cita dos colecciones que corresponden a sintipos, "Lorentz 118 " y "Stuckert 9078", sin consignar el herbario donde se hallan depositadas. Se localizó un ejemplar del segundo de ellos depositado en CORD, el cual consta de cuatro fragmentos que no representan el aspecto de esta entidad en su totalidad. Por su parte, de la colección "Lorentz 118" se localizaron cuatro duplicados depositados en diferentes herbarios, designándose como lectotipo al ejemplar M 0241587 por presentar una planta completa con abundantes órganos reproductivos.

En el protólogo de Alternanthera albida (Moq.) Griseb. f. amentacea Suess. el autor menciona la colección "Lorentz 393" sin consignar el herbario donde se halla depositada. Se localizaron dos ejemplares de la misma, uno en $\mathrm{F}$ y otro en $\mathrm{K}$, designándose como lectotipo al ejemplar $\mathrm{K}$ 000583046 por presentar una planta completa, mientras que el de F consta sólo de fragmentos.

2. Alternanthera altacruzensis Suess., Mitt. Bot. Staatssamml. München 1: 3. 1950. Tipo: Bolivia. Santa Cruz, El Tunalito, 380 m, I. Peredo s.n. (Lectotipo, aquí designado, M 0241623 [foto]!; isolectotipos, AK 267116 [foto]!, BR 6950415[foto]!, CAS 0000312 [foto]!, GB 0047009 [foto]!, GB 0047010 [foto]!, LIL 000415 [Hoja A]!, LIL 000416 [Hoja B]!, LIL 000417 [Hoja C]!, M 0241624 ! [foto]!, MO 247460 [foto]!, TEX 00370682 [foto]!).

En el protólogo de Alternanthera altacruzensis Suess. el autor menciona la colección "Peredo s.n." consignando que se halla depositada en dos herbarios (LIL y M) mediante la cita "Herb. Miguel LilloTucuman; Herb. München". En LIL se encontró un ejemplar montado sobre tres pliegos que presentan anotaciones cruzadas ("Hoja A", "Hoja B" y "Hoja C"), mientras que en $\mathrm{M}$ se hallaron dos ejemplares sin anotaciones cruzadas. Se designa como lectotipo de esta especie al ejemplar M 0241623 dado que en el pliego se encuentra la anotación "Typus!” y en su labelo se encuentra el nombre de la especie, y el nombre del autor seguido del año [1949], todo ello realizado con la grafía del autor. 
3. Alternanthera aquatica (D. Parodi) Chodat, Bull. Soc. Bot. Genève, sér. 2, 18: 257. 1927.

= Alternanthera hassleriana Chodat, Bull. Herb. Boissier, sér. 2, 3: 355. 1903. Tipo: Paraguay. Concepción, Prope Concepcion in lagunis insulae Chaco-y, VIII-1901/1902, E. Hassler 7237 (Lectotipo, aquí designado, G 00102905 [foto]!; isolectotipos, BM 000092437 [foto]!, F $0047577 \mathrm{~F}$ [foto]!, G 00102906 [foto]!, G 00102907 [foto]!, G 00102908 [foto]!, G 00102909 [foto]!, GH 00036957 [foto]!, LIL 000418 [foto]!, P 00622571 [foto]!, P 00622572 [foto]!, UC 934858 [foto]!, $\mathrm{S} \mathrm{n}^{\circ}$ S-R-228 [foto]!).

En el protólogo de Alternanthera hassleriana Chodat el autor menciona la colección "Hassler 7237" sin consignar el herbario donde se halla depositada. Ramella (2016) consideró como holotipo de la especie a G 00102905, mientras que trató como isotipos a los restantes ejemplares que se hallan depositados en el mismo herbario. Sin embargo, según el Art. 40, Nota 1 del ICN (Turland et al., 2018; cfr. McNeill, 2014), como en el protólogo del nombre de la especie se hizo referencia a una colección que consiste de más de un ejemplar y no puede asegurarse que el autor haya usado uno solo de ellos, estos deben ser considerados sintipos; la indicación de holotipo de Ramella (2016) no puede considerarse un error factible de ser corregido a lectotipo, puesto que desde el $1^{\circ}$ de enero de 2001 para efectuar la designación de un lectotipo de un nombre de especie o taxón infraespecífico es necesario consignar dicho término seguido de las palabras "aquí designado" en latín o su equivalente en un idioma moderno (Art. 7.11 y Art. 9.23 del ICN; Turland et al., 2018). En consecuencia, se procedió aquí a efectuar la lectotipificación, designándose al ejemplar G 00102905 dado que su labelo presenta la anotación "Alternanthera hassleriana Chod. nov. sp." realizada con la grafía del autor y asimismo consigna la localidad exacta de colección.

4. Alternanthera brasiliana (L.) Kuntze var. villosa (Moq.) Kuntze, Rev. Gen. Pl. 2: 538. 1891. 三 Telanthera brasiliana (L.) Moq. var. villosa Moq., Prodr. [De Candolle] 13(2): 382. 1849. Tipo: Brasil. Bahia, [monte] Jacobina, 1845, J. S. Blanchet 3881 (Lectotipo [primer paso], P, designado por J. A. Mears, Proc. Acad. Nat. Sci. Philadelphia
129(1): 14. 1977; lectotipo [segundo paso], aquí designado, P 00622523 [foto]!; isolectotipos, BR 000000695112 [foto]!, G 00236944 [foto]!, G 00236945 [foto]!, P 00622522 [foto]!, P 00622524 [foto]!).

= Mogiphanes villosa Mart., Nov. Gen. Spec. Pl. [Martius] 2(1): 33. 1826. Tipo: Brasil. San Pablo, Guaratinguetá, C. F. P. Martius 456 (Lectotipo [primer paso], M, designado por J. A. Mears, Proc. Acad. Nat. Sci. Philadelphia 129(1): 13. 1977; lectotipo [segundo paso], aquí designado, M 0241593 [foto]!; isolectotipo, M 0241594 [foto]! [dos pliegos, el labelo sólo consigna "San Pablo"]).

= Mogiphanes ramosissima Mart., Nov. Gen. Sp. Pl. [Martius] 2(1): 31. 1826. Tipo: Brasil. Sin localidad consignada, C. F. P. Martius 200 (Lectotipo, aquí designado, M 0241591 [foto]!; isolectotipos, G 00236943 [foto]! [el labelo además consigna "Bahia Luschnath 1841"], K 000582988 [foto]!, M 0241590 [foto]!, NY 00324546 [foto]!, P 00622526 [foto]!, P 00622527 [foto]!, P 00622528 [foto]!, PH 00018127 [foto]!, W n ${ }^{\circ} 1889-0269170$ [foto]!, W n 0048170 [foto]!).

= Mogiphanes diffusa Mart., Nov. Gen. Spec. Pl. [Martius] 2(1): 36. 1826. Tipo: Brasil. Pará, sin localidad consignada, F. W. Sieber s.n. (Lectotipo [primer paso], M, designado por J. A. Mears, Proc. Acad. Nat. Sci. Philadelphia 129(1): 13. 1977; lectotipo [segundo paso], aquí designado, M 0241603 [foto]!; isolectotipo, M 0241602 [foto]!).

= Mogiphanes virgata Schrad., Ind. Sem. Hort. Gotting.: 4. 1834. Tipo: Brasil. Sin localidad consignada, sin colector 3239 (Lectotipo, aquí designado, F 0047627F [foto]! [fragmento]).

= Telanthera brasiliana (L.) Moq. f. grisea Chodat, Bull. Herb. Boissier, sér. 2, 1: 433. 1901. Tipo: Paraguay. San Pedro, in dumeto pr. fl. Corrientes, XII-1898/99, E. Hassler 5856 (Lectotipo, aquí designado, G 00103095 [foto]!; isolectotipo, G 00103096 [foto]!).

En el protólogo de Telanthera brasiliana (L.) Moq. var. villosa Moq. el autor menciona la colección "Blanchet 3881" sin consignar en qué herbario se halla depositada. Mears (1977) menciona que el holotipo se encuentra depositado en P; sin embargo, se localizaron varios duplicados en diferentes herbarios. Según el Art. 9.10 del ICN (Turland et al., 2018) esta indicación puede considerarse un error factible de ser corregido, tomándose como 
lectotipo (McNeill, 2014; Prado et al., 2015). Sin embargo, en el herbario $\mathrm{P}$ se localizaron tres pliegos que no presentan anotaciones cruzadas que indiquen que pertenecen al mismo ejemplar. Por lo tanto, es necesario efectuar una lectotipificación de segundo paso, por lo que se designa a tal efecto al ejemplar P 00622523 por ser el más rico en estructuras reproductivas.

En el protólogo de Mogiphanes villosa Mart. el autor cita dos colecciones, una procedente de San Pablo (Guaratinguetá) y la otra de Río de Janeiro (Serra do Mar, Villa das Arêas), sin consignar en qué herbario se hallan depositadas. Mears (1977) citó como holotipo al ejemplar Martius 456 depositado en $\mathrm{M}$, procedente de la primera de las localidades mencionadas; según el Art. 9.10 del ICN (Turland et al., 2018) esta indicación puede considerarse un error factible de ser corregido, tomándose como lectotipo (McNeill, 2014; Prado et al., 2015). Sin embargo, en ese herbario se localizaron dos pliegos de dicho espécimen que no presentan anotaciones cruzadas que indiquen que pertenecen al mismo ejemplar. Por lo tanto, es necesario efectuar una lectotipificación de segundo paso, por lo que se designa a tal efecto al ejemplar M 0241593 por contar en su labelo con la localidad exacta de colección.

En el protólogo de Mogiphanes ramosissima Mart. el autor menciona "Crescit in sylvis umbrosis ad Chapada, vicum Minarum Novarum, in Provincia Minas Gëraes"; la colección fue realizada por el propio Martius, ya que si bien su nombre no está mencionado, en su obra Nova Genera et Species Plantarum sólo se indica el nombre del colector cuando se trata de otra persona; no se consigna el herbario en el que se halla depositada la misma. Se han localizado varios duplicados en diversos herbarios que no presentan indicación de localidad, sino que su labelo consigna "Martii Herbar. Florae. Brasil. $N^{\circ} 200 "$ debajo del nombre de la especie, designándose como lectotipo a M 0241591 por presentar dos ramas con abundantes estructuras reproductivas.

En el protólogo de Mogiphanes diffusa Mart. el autor menciona la colección "Sieber s.n." sin consignar en qué herbario se halla depositada. Mears (1977) citó como holotipo de este taxón a un ejemplar depositado en $\mathrm{M}$; sin embargo, en este herbario se localizaron dos pliegos de dicho espécimen que no presentan anotaciones cruzadas que indiquen que pertenecen al mismo ejemplar. Según el Art. 9.10 del ICN (Turland et al., 2018) la indicación de Mears (1977) puede considerarse un error factible de ser corregido, tomándose como lectotipo (McNeill, 2014; Prado et al., 2015). Por el motivo antes mencionado, es necesario efectuar una lectotipificación de segundo paso, designándose a tal efecto al ejemplar M 0241603 por presentar una planta completa.

En el protólogo de Mogiphanes virgata Schrad. el autor no indicó el tipo, ni el colector, ni la localidad de colección. Como único elemento del material original se ha localizado un fragmento en $\mathrm{F}$ correspondiente a un ejemplar que se hallaba depositado en B y que actualmente se haya destruido (R. Vogt, curador de B, com. pers.). Junto al fragmento, se conserva la fotografía del ejemplar, donde se observa que el pliego presentaba el nombre de la especie, por lo cual es probable que el mismo haya sido empleado por el autor para efectuar la diagnosis de la especie. Por todo lo expuesto, se designa aquí como lectotipo a dicho fragmento.

En el protólogo de Telanthera brasiliana (L.) Moq. f. grisea Chodat el autor menciona la colección "Hassler 5856" sin consignar en qué herbario se halla depositada. Se localizaron dos ejemplares cuyos labelos coinciden en un todo con el protólogo, designándose como lectotipo al ejemplar G 00103095 porque la localidad indicada en su labelo coincide literalmente con la citada en el protólogo ("in dumeto pr. fl. Corrientes"), a lo que se suma el hecho de que se consigna el nombre completo del taxón con la grafía del autor; por otro lado el labelo de G 00103096 consigna "In regione fluminis Corrientes". Se han localizado otros dos ejemplares (BM 000092420 ["In regione Yerbalium de Maracayú Paraguaria euro-austra"] y NY 00341975 [“Gran Chaco, Loma Clavel"]) que coinciden en el colector y número de colecta, pero que difieren en la localidad de colección.

5. Alternanthera caracasana Kunth, Nov. Gen. Sp. [Humboldt, Bonpland \& Kunth] 2: 205. 1818.

= Alternanthera villiflora Scheele, Linnaea 22: 149. 1849. Tipo: Estados Unidos de América. Texas, San Antonio, 1846, F. Lindheimer 512 (Lectotipo [primer paso], $\mathrm{K}$ designado por $\mathrm{R}$. Melville, Kew Bull. 13: 175. 1958; lectotipo [segundo paso], aquí designado, K 000848119 


\section{N. D. Bayón y D. A. Giuliano - Lectotipificaciones en Amaranthaceae}

[foto]!; isolectotipos, BM 001024725 [foto]!, GH 00036940 [foto]!, K 000848117 [foto]!, LE 00012017 [foto]!, P 00622503 [foto]!, PH 00024969 [foto]!, US 00102775 [foto]!, US 00102776 [foto]!).

= Alternanthera macrorhiza Hauman, Bull. Jard. Bot. État. Bruxelles 18: 114. 1946. Tipo: República Democrática del Congo. Katanga, Katuba, 25-I1927, P. Quarré 21 (Lectotipo [primer paso], BR, designado por J. A. Mears, Proc. Acad. Nat. Sci. Philadelphia 129(1): 11. 1977; lectotipo [segundo paso], aquí designado, BR 0000008819444 [foto]!; isolectotipos, BR 0000008819390 [foto]!, BR 0000008819437 [foto]!, GH 00036977 [foto]!, KIP 118450953 [foto]!, PRE 07756890 [foto]!).

En el protólogo de Alternanthera villiflora Scheele el autor menciona la colección "Lindheimer s.n." sin consignar en qué herbario se halla depositada. Melville (1958) citó como isotipo de este taxón a un ejemplar depositado en K; según el Art. 9.10 del ICN (Turland et al., 2018) esta indicación puede considerarse un error factible de ser corregido, tomándose como lectotipo (McNeill, 2014; Prado et al., 2015). Sin embargo, en ese herbario se localizaron dos pliegos de dicho espécimen que no presentan anotaciones cruzadas que indiquen que pertenecen al mismo ejemplar. Por lo tanto, es necesario efectuar una lectotipificación de segundo paso, por lo que se designa a tal efecto al ejemplar K 000848119 por presentar una planta completa con abundantes estructuras vegetativas y reproductivas.

En el protólogo de Alternanthera macrorhiza Hauman el autor menciona la colección "Quarré 21 " sin indicar en qué herbario se halla depositada. Mears (1977) citó como holotipo a un ejemplar depositado en BR; sin embargo, se localizaron varios duplicados en diferentes herbarios. Según el Art. 9.10 del ICN (Turland et al., 2018) esta indicación puede considerarse un error factible de ser corregido, tomándose como lectotipo (McNeill, 2014; Prado et al., 2015). Sin embargo, en BR se localizaron tres pliegos que no presentan anotaciones cruzadas que indiquen que pertenecen al mismo ejemplar. Por lo tanto, es necesario efectuar una lectotipificación de segundo paso, por lo que se designa a tal efecto a BR 0000008819444 por presentar una planta rica en estructuras de todo tipo.
6. Alternanthera cinerella Suess., Repert. Spec. Nov. Regni Veg. 39: 3. 1935. Tipo: Argentina. Tucumán, Tafí, Sierra del Cajón, Quebrada de los Bateones, 2200 m, 1-V-1926, S. Venturi 4233 (Lectotipo, aquí designado, M 0241605 [foto]!; isolectotipos, CORD 00002443!, LP 002710 [foto]!, M 0241606 [foto]!, US 00102757 [foto]!).

En el protólogo de Alternanthera cinerella Suess. el autor menciona la colección "Venturi 4233" consignando que se halla depositada en los herbarios LP y M. En M se localizaron dos pliegos que no presentan anotaciones cruzadas que indiquen que pertenecen al mismo ejemplar; ambos presentan la indicación "Typus" realizada por el autor. Se designa como lectotipo al ejemplar $\mathrm{M}$ 0241605 por presentar plantas de mayor tamaño.

7. Alternanthera hirtula (Mart.) R. E. Fr., Ark. Bot. 16(12): 18. 1920.

= Telanthera rosea (Morong) Chodat var. cinnabarina Chodat, Bull. Herb. Boissier, sér. 2, 1 : 433. 1901. Tipo: Paraguay. Canindeyú, in campo pr. Igatimí, IX-1898/1899, E. Hassler 4691 (Lectotipo [primer paso], G, designado por T. M. Pedersen, Bonplandia 10 (1-4): 84. 2000; lectotipo [segundo paso], aquí designado, G 00102925 [foto]!; isolectotipos, BM 000092446 [foto]!, G 00102923 [foto]!, G 00102924 [foto]!, G 00102926 [foto]!, G 00102927 [foto]!, GH 00036972 [foto]!, K 000582990 [foto]!, P 00622596 [foto]!, P 00622597 [foto]!).

= Telanthera rosea (Morong) Chodat var. atropurpurea Chodat, Bull. Herb. Boiss., sér. 2, 1: 433. 1901. Tipo: Paraguay. Canindeyú, Sierra de Maracayú, in regione fluminis Tapiraguay, VIII1898/1899, E. Hassler 4359 (Lectotipo [primer paso], designado por R. Chodat, Bull. Soc. Bot. Genève, sér. 2, 18: 277. 1927; lectotipo [segundo paso], aquí designado, G 00103020 [foto]!; isolectotipos, BM 000993128 [foto]! [montado en la misma hoja que Hassler 4946], G 00103021 [foto]! [el labelo consigna "In campo Apepu"], UC 940460 [foto]!; probable isolectotipo, G 00103019 [foto]! [no se consigna localidad]).

$=$ Telanthera rosea (Morong.) Chodat var. pallens Chodat, Bull. Herb. Boiss., sér. 2, 1: 433. 1901. Tipo: Paraguay. Canindeyú, Ipé hú, X-1898/1899, E. Hassler 4939 (Lectotipo [primer paso], G, designado por T. M. Pedersen, Adansonia 
sér. 3, 19(2): 220. 1997; lectotipo [segundo paso], aquí designado, G 00103012 [foto]! [dos pliegos]; probables isolectotipos, BM 000092427 [foto]!, G 00103013 [foto]!, G 00103014 [foto]!, G 00103015 [foto]!, K 000582992 [foto]! [los labelos de estos cinco ejemplares consignan "Sierra de Maracayúu”]).

En el protólogo de Telanthera rosea (Morong) Chodat var. cinnabarina Chodat el autor menciona la colección "Hassler 4691" sin consignar en qué herbario se halla depositada. Pedersen (2000) citó como holotipo a un ejemplar depositado en $\mathrm{G}$; sin embargo, se localizaron varios duplicados en diferentes herbarios y no puede asegurarse que el autor haya usado uno solo de ellos. Según el Art. 9.10 del ICN (Turland et al., 2018) esta indicación puede considerarse un error factible de ser corregido, tomándose como lectotipo (McNeill, 2014; Prado et al., 2015). No obstante, en $\mathrm{G}$ se encontraron tres pliegos que no presentan anotaciones cruzadas que indiquen que pertenecen al mismo ejemplar. Ramella (2016) consideró como holotipo de la especie a G 00102925, mientras que trató como isotipos a los restantes ejemplares que se hallan depositados en el mismo herbario. La indicación de holotipo de Ramella (2016) no puede considerarse un error factible de ser corregido a lectotipo, puesto que desde el $1^{\circ}$ de enero de 2001 para efectuar la designación de un lectotipo de un nombre de especie o taxón infraespecífico es necesario consignar dicho término seguido de las palabras "aquí designado" en latín o su equivalente en un idioma moderno (Art. 7.11 y Art. 9.23 del ICN; Turland et al., 2018). Por lo tanto, es necesario efectuar una lectotipificación de segundo paso, por lo que se designa a tal efecto al ejemplar $G$ 00102925 por presentar abundantes estructuras vegetativas y reproductivas.

En el protólogo de Telanthera rosea (Morong) Chodat var. atropurpurea Chodat el autor menciona dos colecciones que corresponden a sintipos, "Hassler 4359" у "Hassler 4946", sin consignar el herbario donde se hallan depositadas. Posteriormente, cuando Chodat (Chodat \& Rehfous, 1927) realiza la transferencia de este taxón al rango de subvariedad (Alternanthera hirtula (Mart.) R. E. Fr. var. robusta Chodat subvar. atropurpurea (Chodat) Chodat), menciona solamente al primero de ellos, considerándose de este modo que se ha efectuado una lectotipificación (McNeill, 2014;
Prado et al., 2015). De este ejemplar se han localizado en $G$ tres pliegos que no presentan anotaciones cruzadas que indiquen que pertenecen al mismo ejemplar y un ejemplar adicional en UC, designándose como lectotipo de segundo paso a G 00103020 por presentar abundantes estructuras vegetativas y reproductivas.

En el protólogo de Telanthera rosea (Morong.) Chodat var. pallens Chodat el autor menciona la colección "Hassler 4939" sin consignar en qué herbario se halla depositada. Pedersen (1997) citó como holotipo a un ejemplar depositado en $\mathrm{G}$; sin embargo, se localizaron varios duplicados en diferentes herbarios y no puede asegurarse que el autor haya usado uno solo de ellos. Según el Art. 9.10 del ICN (Turland et al., 2018) esta indicación puede considerarse un error factible de ser corregido, tomándose como lectotipo (McNeill, 2014; Prado et al., 2015). No obstante, en G se localizaron cuatro duplicados que no presentan anotaciones cruzadas que indiquen que pertenecen al mismo ejemplar. Ramella (2016) consideró como holotipo de la especie a G 00103012, mientras que trató como isotipos a los restantes ejemplares que se hallan depositados en el mismo herbario. La indicación de holotipo de Ramella (2016) no puede considerarse un error factible de ser corregido a lectotipo, puesto que desde el $1^{\circ}$ de enero de 2001 para efectuar la designación de un lectotipo de un nombre de especie o taxón infraespecífico es necesario consignar dicho término seguido de las palabras "aquí designado" en latín o su equivalente en un idioma moderno (Art. 7.11 y Art. 9.23 del ICN; Turland et al., 2018). Por lo tanto, es necesario efectuar una lectotipificación de segundo paso, por lo que se designa a tal efecto al ejemplar $G$ 00103012 por ser el único cuyo labelo menciona la localidad indicada en el protólogo, sumado al hecho de que presenta plantas con abundantes estructuras vegetativas y reproductivas. Este espécimen se halla montado en dos pliegos que presentan el mismo número de herbario ( $\mathrm{G} \mathrm{n}^{\circ} 7697$, cada uno seguido por los números correlativos 191 y 192), los cuales originalmente pertenecieron al herbario de Hassler.

8. Alternanthera lanceolata (Benth.) Schinz, Nat. Planzenfam., ed. 2 [Engler \& Plantl] 16c: 75. 1934. $\equiv$ Brandesia lanceolata Benth., Pl. Hartw.: 247. 1846. Tipo: Colombia. Cauca, Popayán, 1843, K. 
T. Hartweg 1365 (Lectotipo, aquí designado, K 000583022 [foto]!; isolectotipos, BM 000993109 [foto]!, E 00296886 [foto]!, K 000583021 [foto]!, P 000622556 [foto]!, P 00622557 [foto]!).

= Alternanthera lehmannii Hieron., Bot. Jahrb. Syst. 20 (Beih. 49): 8. 1895. Tipo: Colombia. Prope Popayán, 1700-1800 m, F. C. Lehmann 5617 (Lectotipo, aquí designado, B 100242316 [foto]!; isolectotipos, F 0047578F [foto]!, GH 00036958 [foto]!, K 000583023 [foto]!, K 000583024 [foto]!, M 0241643 [foto]!, US 00102761 [foto]!).

= Brandesia mexicana Schltdl., Linnaea 7: 392. 1832. Tipo: México. Prope Jalapam, V-1829, C. J. W. Schiede s.n. (Lectotipo, aquí designado, HAL 0098009 [foto]!; isolectotipos, BM 000993098 [foto]!, MO 101548 [foto]! [el labelo consigna el número de colección 70]; probable isolectotipo, $\mathrm{P}$ 00622516 [foto]! [el labelo no consigna localidad y presenta el número de colección 70]).

$=$ Telanthera microcephala Moq., Prodr. [De Candolle] 13(2): 371. 1849. Tipo: México. Oaxaca, $5000 \mathrm{ft}$., H. Galeotti 426 (Lectotipo, aquí designado, P 00622513 [foto]!; isolectotipos, F $0047635 \mathrm{~F}$ [foto]!, [G-DC] G 00689262 [foto]!, GH 00037141 [foto]!, P 00622514 [foto]!, P 00622515 [foto]!, US 00102764 [foto]!).

En el protólogo de Brandesia lanceolata Benth. el autor menciona la colección "Hartweg 1365" sin consignar el herbario donde se halla depositada. Se localizaron varios duplicados en diversos herbarios, designándose como lectotipo al ejemplar K 000583022 por presentar abundantes estructuras vegetativas y reproductivas. Se ha localizado otro ejemplar (P 00622555 [“Quito"]) que coincide en el colector y número de colecta, pero que difiere en la localidad de colección.

En el protólogo de Alternanthera lehmannii Hieron. el autor menciona la colección "Lehmann 5617 " sin consignar el herbario donde se halla depositada. Se localizaron varios duplicados procedentes de distintos herbarios, designándose como lectotipo al ejemplar B 100242316 por presentar abundantes estructuras vegetativas y reproductivas.

En el protólogo de Brandesia mexicana Schltdl. el autor menciona una colección indicando "pr. Jalapam Majo fl.”, sin consignar el herbario donde se halla depositada. Se localizaron tres ejemplares procedentes de dicha localidad colectados en el mes de mayo por Schiede, dos de ellos sin número de colección y el restante con el número 70, designándose como lectotipo al ejemplar HAL 0098009 por presentar abundantes estructuras vegetativas y reproductivas. Un cuarto ejemplar depositado en P muestra una labelo con el nombre del taxón y el número 70 colectado en México por Schiede., formando parte muy probablemente del material original.

En el protólogo de Telanthera microcephala Moq. el autor menciona dos colecciones que corresponden a sintipos, "Galeotti 426" " "Jurgensen 413", indicando "v. s. comm. a cl. Galeotti et h. Mus. Paris. et DC.". Después de examinar ambas colecciones, se designa como lectotipo al ejemplar P 00622513, correspondiente a la primera de ellas, por presentar abundantes estructuras vegetativas y reproductivas.

9. Alternanthera micrantha R. E. Fr., Ark. Bot. 16(12): 14. 1920. Tipo: Brasil. Santa Catarina [consignado en el protólogo como Rio Grande do Sul], ca. Estación de ferrocarril de Rio Uruguay, 400 m, 23-II-1916, P. Dusén 17728 (Lectotipo [primer paso], S, designado por T. M. Pedersen, Adansonia, sér. 3, 19(2): 220. 1997; lectotipo [segundo paso], aquí designado, $\mathrm{S} \mathrm{n}^{\circ} \mathrm{S}-\mathrm{R}-231$ [foto]!; isolectotipos, K 000582995 [foto]!, GH 00036961 [foto]!, MO 2114690 [foto]!, US 00102763 [foto]!, S no S-07-12318 [foto]!).

En el protólogo de Alternanthera micrantha R. E. Fr. el autor menciona la colección "Dusén 17728 " sin consignar en qué herbario se halla depositada. Pedersen (1997) citó como holotipo a un ejemplar depositado en $\mathrm{S}$; sin embargo, se localizaron varios duplicados en diferentes herbarios y no puede asegurarse que el autor haya usado uno solo de ellos. Según el Art. 9.10 del ICN (Turland et al., 2018) esta indicación puede considerarse un error factible de ser corregido, tomándose como lectotipo (McNeill, 2014; Prado et al., 2015). Sin embargo, en S se han localizado dos pliegos que no presentan anotaciones cruzadas que indiquen que pertenecen al mismo ejemplar. Por lo tanto, es necesario efectuar una lectotipificación de segundo paso, por lo que se designa a tal efecto al ejemplar S n ${ }^{\circ} \mathrm{S}-\mathrm{R}-231$ por presentar abundantes estructuras vegetativas y reproductivas. 
10. Alternanthera microphylla R. E. Fr., Nova Acta Regiae Soc. Sci. Upsal., ser. 4, 1: 154. 1905. Tipo: Argentina. Jujuy, Santa Catalina, Santa Catalina, 3650 m, 14-I-1901, F. Claren s.n. in Herb. Kurtz 11387 (Lectotipo, aquí designado, CORD 00002449 !).

En el protólogo de Alternanthera microphylla R. E. Fr. el autor menciona cuatro colecciones que corresponden a sintipos, "Kurtz 11350" (CORD 00002447 !, S n ${ }^{\circ}$ S-R-232 [foto]!), "Kurtz 11351" (CORD 00002448!), “Kurtz 11387” y "Fries 973” (S nº S-R-233 [foto]!), sin consignar en qué herbario se hallan depositadas. Se designa como lectotipo al ejemplar Claren s.n. in Herb. Kurtz 11387 (CORD) por presentar numerosas plantas bien desarrolladas y de mayor tamaño.

11. Alternanthera microphylla R. E. Fr. var. maior Suess., Lilloa 4: 127. 1939. Tipo: Argentina. Jujuy, Tumbaya, Volcán, 2400 m, 13-II-1927, S. Venturi 4842 (Lectotipo, aquí designado, LIL 000420 [foto]!; isolectotipos, BAB [foto]!, BAF!, CAS 0000467 [foto]!, LP 002711 [foto]!, US 00102765 [foto]!).

En el protólogo de Alternanthera microphylla R. E. Fr. var. maior Suess., el autor menciona dos colecciones que corresponden a sintipos, "Venturi 4842" y "Venturi 6859", sin consignar en qué herbario se hallan depositadas. Se ha localizado sólo a la primera de ellas. Se designa como lectotipo al ejemplar LIL 000420 por presentar plantas con abundantes estructuras vegetativas y reproductivas.

12. Alternanthera paronychioides A. St.-Hil. subsp. chacoensis (Morong) Pedersen ex Ramella, Candollea 71(2): 314. 2016.

$=$ Alternanthera morongii Uline, Publ. Field Columb. Mus., Bot. Ser., 1(5): 418. 1899. Tipo: Paraguay. Central, "Central Paraguay", 1888, T. Morong 40 (Lectotipo, aquí designado, F 0047581F [foto]!; isolectotipos, BM 000092436 [foto]!, CORD 00002450!, F 0047580F [foto]!, G 00103024 [foto]!, GH 00036963 [foto]!, NDG 04259 [foto]!, US 00102767 [foto]!).

En el protólogo de Alternanthera morongii Uline el autor menciona la colección "Morong 40" depositada en $\mathrm{F}$ indicando que existen dos pliegos, los cuales no presentan anotaciones cruzadas que indiquen que pertenecen al mismo ejemplar. Ramella (2016) consideró como holotipo de la especie a F 0047580F, mientras que trató como isotipos a los restantes ejemplares que se hallan depositados en BM, F y G. Sin embargo, según el Art. 40, Nota 1 del ICN (Turland et al., 2018; cfr. McNeill, 2014), como en el protólogo del nombre de la especie se citan dos ejemplares depositados en el mismo herbario, estos deben ser considerados sintipos; la indicación de holotipo de Ramella (2016) no puede considerarse un error factible de ser corregido a lectotipo, puesto que desde el $1^{\circ}$ de enero de 2001 para efectuar la designación de un lectotipo de un nombre de especie o taxón infraespecífico es necesario consignar dicho término seguido de las palabras "aquí designado" en latín o su equivalente en un idioma moderno (Art. 7.11 y Art. 9.23 del ICN; Turland et al., 2018). Por lo tanto, se designa como lectotipo al ejemplar $\mathrm{F}$ $0047581 \mathrm{~F}$ por presentar dos plantas, una de ellas con gran desarrollo.

13. Alternanthera paronychioides A. St.-Hil. subsp. pilosa (Moq.) Pedersen ex Ramella, Candollea 71(2): 314. 2016.

= Alternanthera boliviana Rusby subsp. amentacea Suess., Repert. Spec. Nov. Regni Veg. 42: 51. 1937. TIPO. Argentina. Buenos Aires, Dock Sur, 1-V-1926, L. R. Parodi 7219 (Lectotipo, B 100242324 [foto]!, aquí designado; isolectotipo, BAA 00001202 [foto]!).

En el protólogo de Alternanthera boliviana Rusby subsp. amentacea Suess. el autor menciona la colección "Parodi 7219", consignando que se halla depositada en los herbarios B y W. Se designa como lectotipo al ejemplar B 100242324 dado que es el único disponible de ambos, ya que el espécimen de W ha sido destruido (Pedersen, 2000).

14. Alternanthera philoxeroides (Mart.) Griseb., Abh. Königl. Ges. Wiss. Göttingen 24: 36. 1879.

= Achyranthes paludosa Bunbury, Proc. Linn. Soc. London 1: 109. 1841. Tipo: Argentina. Buenos Aires, wet ditches near Buenos Aires, Bunbury s.n. (Lectotipo [primer paso], BR, designado por J. A. Mears, Proc. Acad. Nat. Sci. Philadelphia 129(1): 14. 1977; lectotipo [segundo paso], aquí designado, BR 0000013460006 [foto]!; isolectotipo, BR 0000013459994 [foto]!). 
En el protólogo de Achyranthes paludosa Bunbury el autor no indicó material tipo. Mears (1977) citó como tipo ["authentic specimen"] a un ejemplar depositado en BR colectado por el autor; según el Art. 9.3 del ICN (Turland et al., 2018) este espécimen debe considerarse un lectotipo. Sin embargo, en BR se han localizado dos pliegos que no presentan anotaciones cruzadas que indiquen que pertenecen al mismo ejemplar. Por lo tanto, es necesario efectuar una lectotipificación de segundo paso, por lo que se designa a tal efecto al ejemplar BR 0000013460006 por contar con dos fragmentos con estructuras vegetativas y reproductivas.

15. Alternanthera pumila $O$. Stützer, Repert. Spec. Nov. Regni Veg. Beih. 88: 45. 1935. Tipo: Argentina. Córdoba, XII-1925, 1800 m, W. Lossen 1 (Lectotipo, aquí designado, M 0241658 [foto]!; isolectotipos, G 0048321 [foto]!, F $0047587 \mathrm{~F}$ [foto]!, PH 00002157 [foto]!, SI 033030 [foto]!).

= Alternanthera pumila O. Stützer var. coarctata O. Stützer, Repert. Spec. Nov. Regni Veg. Beih. 88: 45. 1935. Tipo: Argentina. Córdoba, Cruz del Eje, XI-1904, T. J. V. Stuckert 14508 (Lectotipo, aquí designado, G 00418322 [foto]!; isolectotipo, CORD 00002451!).

En el protólogo de Alternanthera pumila O. Stützer la autora menciona la colección "Lossen 1" consignando que se halla depositada en los herbarios G, GH y M. Se designa aquí como lectotipo al ejemplar M 0241658 dado que presenta la anotación “Typus" con la grafía de la autora y por presentar una planta mejor desarrollada.

En el protólogo de Alternanthera pumila O. Stützer var. coarctata O. Stützer la autora menciona dos colecciones que corresponden a sintipos, "Stuckert 14508" y "Stuckert 19908", consignando que ambas se hallan depositadas en G. Después de examinar ambas colecciones, se designa como lectotipo al ejemplar G 00418322 correspondiente a la primera de ellas por presentar mayor número de plantas.

16. Alternanthera pungens Kunth, Nov. Gen. Sp. [Humboldt, Bonpland \& Kunth] 2: 206. 1818.

= Illecebrum obliquum Schumach. \& Thonn., Beskr. Guin. Pl. 142. 1827. Tipo: Guinea, Thonning s.n. (Lectotipo, aquí designado, C 10004022 [foto]!; isolectotipos, C 10004021 [foto]!, P 004466166 [foto]!).
En el protólogo de Illecebrum obliquum Schumach. \& Thonn. los autores mencionan una colección realizada en Guinea por Thonning sin consignar el herbario donde se halla depositada. Se han localizado tres ejemplares colectados en Guinea por Thonning, uno en $\mathrm{P}$ y dos en $\mathrm{C}$, los cuales no presentan anotaciones cruzadas que indiquen que pertenecen al mismo ejemplar, designándose como lectotipo al ejemplar C 10004022 por presentar una planta con mayor cantidad de estructuras vegetativas y reproductivas.

17. Alternanthera reineckii Briq., Annuaire Conserv. Jard. Bot. Genève 3: 151. 1899. Tipo: Brasil. Rio Grande do Sul, Porto Alegre, San Joao, 15-XII-1897, E. M. Reineck \& J. Czermak 156 (Lectotipo, aquí designado, FR 0031147 [foto]!; isolectotipos, E 00394845 [foto]!, G 00236940 [foto]!, GOET 000079 [foto]!, JE 00013049 [foto]!, JE 00013050 [foto]!, K 000583080 [foto]!, M 0241663 [foto]!, MG HG2598 [foto]!, P 00622585 [foto]!, P 00622586 [foto]!, SI 033039 [foto]!).

$=$ Alternanthera pilosa Moq. f. petiolata Chodat, Bull. Herb. Boissier, sér. 2, 3: 355. 1903. Tipo: Paraguay. Central, Ypacaray, VI-1898/1899, E. Hassler 3039 (Lectotipo, aquí designado, G 00103101 [foto]!; isolectotipos, G 00103099 [foto]!, G 00103100 [foto]!).

= Alternanthera pilosa Moq. var. microphylla Chodat, Bull. Herb. Boissier, sér. 2, 3: 355. 1903. Tipo: Paraguay. Cordillera, Cerros de Tobaty, IX1900, E. Hassler 6261 (Lectotipo, aquí designado, G 00103097 [foto]!; isolectotipos, BM 0092445 [foto]! [el labelo consigna "In regionis Cordillerae centralis"], G 00103098 [foto]!, G 00103118 [foto]!, K 000583079 [foto]!, P 00622587 [foto]!, UC 934859 [foto]!).

En el protólogo de Alternanthera reineckii Briq. el autor menciona la colección "Reineck \& Czermak 156" sin consignar en qué herbario se halla depositada. Se han localizado numerosos duplicados, designándose como lectotipo al ejemplar FR 0031147 por presentar varias plantas con abundantes órganos vegetativos y reproductivos. Conviene aclarar que solo los ejemplares FR 0031147 y JE 00013049 presentan el número de colección 156, mientras que los restantes, en cuyos labelos se consignan la localidad y la fecha de colección indicadas en el protólogo, exhiben el 
número de colecta 46 , lo cual se considera que se debe a un error.

En el protólogo de Alternanthera pilosa Moq. f. petiolata Chodat el autor menciona la colección "Hassler 3039" sin consignar en qué herbario se halla depositada. Se han localizado tres pliegos en $\mathrm{G}$ que no presentan anotaciones cruzadas que indiquen que pertenecen al mismo ejemplar, designándose como lectotipo al ejemplar G 00103101 dado que su labelo presenta la anotación “Typo" realizada con la grafía del autor.

En el protólogo de Alternanthera pilosa Moq. var. microphylla Chodat el autor menciona la colección "Hassler 6261" sin consignar en qué herbario se halla depositada. Se han localizado varios duplicados en diferentes herbarios, designándose como lectotipo al ejemplar G 00103097 dado que su labelo presenta la anotación del nombre del taxón infraespecífico realizada con la grafía del autor.

18. Alternanthera rufa (Mart.) D. Dietr., Syn. Pl. [D. Dietrich] 1: 866. 1839. E Brandesia rufa Mart., Nov. Gen. Sp. [Martius] 2: 26. 1826. Tipo: Brasil. Minas Gerais, Río da Onca, Martius s.n. (Lectotipo, aquí designado, M 0241665 [foto]!; isolectotipo, P 00622588 [foto]!).

En el protólogo de Brandesia rufa Mart. el autor menciona dos colecciones que corresponden a sintipos procedentes de Brasil, una de ellas realizada en el estado de San Pablo (M 0241666 [foto]!) y la otra en el de Minas Gerais, sin consignar en qué herbario se hallan depositadas. Se designa como lectotipo al ejemplar M 0241665 procedente de Minas Gerais por presentar una rama con mayor cantidad de hojas e inflorescencias.

19. Alternanthera scandens Herzog, Meded. Rijks-Herb. 46: 7. 1922. Tipo: Bolivia. Yacuiba, ca. 650 m, T. C. J. Herzog 1062 (Lectotipo, aquí designado, B 100242306 [foto]!; isolectotipos, G 00236939 [foto]!, JE 00013051[foto]!, M 0241668 [foto]!, S no S-R-236 [foto]!).

En el protólogo de Alternanthera scandens Herzog el autor menciona la colección "Herzog 1062 " sin consignar en qué herbario se halla depositada. Se han localizado varios duplicados en diferentes herbarios, designándose como lectotipo al ejemplar B 100242306 por estar compuesto por una rama con abundantes hojas e inflorescencias.

20. Alternanthera suessenguthii Covas, Revista Argent. Agron. 6: 297. 1939. Alternanthera lorentzii Suess., Repert. Spec. Nov. Regni Veg. 42: 53. 1937, hom. illeg., non Uline 1899. Tipo: Argentina. Córdoba, prope Estanzia Germania, VI/XII-1874, P. G. Lorentz 44c (Lectotipo, aquí designado, B 100242315 [foto]!; isolectotipos, BM 000992124 [foto]!, P 00622529 [foto]!).

Alternanthera suessenguthii fue publicado como nombre de reemplazo de $A$. lorentzii Suess., non Uline. En el protólogo de Alternanthera lorentzii Suess. el autor menciona dos colecciones que corresponden a sintipos, "Lorentz 44c" depositada en B y "Stuckert 12083" depositada en CORD y G. Después de examinar ambas colecciones, se designa como lectotipo al ejemplar B 100242315 correspondiente a la primera de ellas por presentar tres plantas con abundantes órganos vegetativos y reproductivos.

21. Blutaparon portulacoides (A. St.-Hil.) Mears, Taxon 31(1): 115. 1982. $\equiv$ Philoxerus portulacoides A. St.-Hil., Voy. Distr. Diam. 2: 436. 1833. Tipo: Brasil. Río de Janeiro, 1816/1821, St. Hilaire Catal. $\mathrm{A}^{2}, 82,304$ (Lectotipo [primer paso], P, designado por J. A. Mears, Taxon 31: 115. 1982; lectotipo [segundo paso], aquí designado, P 00622606 [foto]!; isolectotipo, P 00622607 [foto]!).

= Telanthera philoxeroides (Mart.) Moq. var. carnosa Moq., Prodr. [De Candolle] 13(2): 363. 1849. Tipo: Uruguay. Maldonado, Isla Gorriti, "Gorrita ad Plata", J. Tweedie s.n. (Lectotipo, aquí designado, K 000583058 [foto]!; isolectotipos, K 000583057 [foto]!, K 000583059 [foto]!).

En el protólogo de Philoxerus portulacoides A. St.-Hil. el autor menciona "Var. $\alpha$ prope Sebastianopolim" aludiendo a una colección realizada por él mismo, sin consignar el número de colecta ni el herbario donde se halla depositada. Mears (1982) indicó que el tipo se halla depositado en $\mathrm{P}$, designando de este modo al lectotipo de este nombre (Art. $7.11 \mathrm{Ej}$. 13 del ICN; Turland et al., 2018); sin embargo, en este herbario se localizaron dos pliegos de dicha colección con la firma del autor, que no presentan anotaciones cruzadas que 
indiquen que pertenecen al mismo ejemplar. Por lo tanto, es necesario efectuar una lectotipificación de segundo paso, designándose a tal efecto al ejemplar P 00622606 por presentar mayor abundancia de estructuras reproductivas.

En el protólogo de Telanthera philoxeroides (Mart.) Moq. var. carnosa Moq. el autor menciona "In ins. Gorritâ ad Plata. (Tweedie!). (v.s. in h. Hook.)". En K se localizaron tres ejemplares montados en un mismo pliego. Se designa como lectotipo al ejemplar K 000583058 por presentar tres plantas con mayor desarrollo de raíces, tallos e inflorescencias.

22. Chamissoa acuminata Mart., Nova Acta Phis.Med. Acad. Caes. Leop.-Carol. Nat. Cur. 13: 286. 1826.

= Chamissoa blanchetii Moq., Prodr. [De Candolle] 13(2): 251. 1849. Tipo: Brasil. Bahia, Jacobina, 1842, J. S. Blanchet 3576 (Lectotipo, aquí designado, G-DC G 00689344 [foto]!; isolectotipos, BM 000993088 [foto]!, BR 000000695115 [foto]!, C 10005381 [foto]!, G 00398392 [foto]!, G 0000398393 [foto]! [dos pliegos], P 00609926 [foto]!, P 00609927 [foto]!, P 00609928 [foto]!).

En el protólogo de Chamissoa blanchetii Moq. el autor menciona la colección "Blanchet 3576" consignando "v. s. in h. DC". Sohmer (1977) designó como lectotipo a un ejemplar depositado en BM. Sin embargo, se han localizado dos ejemplares originalmente pertenecientes al herbario de De Candolle: uno en G-DC y el otro en P. Por lo tanto, uno de estos dos ejemplares debe ser designado como lectotipo. En consecuencia, se rechaza la lectotipificación propuesta por Sohmer (1977) teniendo en cuenta el artículo 9.19(c) del ICN (Turland et al., 2018). De los dos ejemplares del herbario de De Candolle se designa como lectotipo al depositado en G-DC (G 00689344) puesto que su labelo consigna la localidad exacta de colecta ("Jacobine"), mientras que el depositado en $\mathrm{P}$ consigna "Bahia" que es el estado donde se encuentra ubicada la localidad tipo.

23. Chamissoa maximiliani Mart. ex Moq., Prodr. [De Candolle] 13(2): 251. 1849. Tipo: Brasil. Sin localidad consignada, 1837, C. F. P. S. Martius 180 (Lectotipo [primer paso], G, designado por S. H. Sohmer, Bull. Torrey Bot. Club 104(2): 122. 1977; lectotipo [segundo paso], aquí designado, G-DC G 00689321 [foto]!; isolectotipos, G 00429765 [foto]!, GH 0037047 [foto]!, M 0121089 [foto]!, MO 247478 [foto]!, NY 00324474 [foto]!, P 00799260 [foto]!).

= Chamissoa maximiliani Moq. var. procumbens Seub., Fl. Bras. 5: 243. 1875. Tipo: Brasil. Sin localidad consignada, J. G. F. Riedel 699 (Lectotipo, aquí designado, P 04924945 [foto]!; isolectotipo, M 0241359 [foto]!).

= Chamissoa maximiliani Moq. var. pubescens Chodat, Bull. Herb. Boissier 7, Append. 1: 63. 1899. Tipo: Paraguay. Cordillera, Cordillera de Altos, VI-1885/1895, E. Hassler 467 (Lectotipo, aquí designado, G 00103254 [foto]! [dos pliegos]; isolectotipo, G 00103255 [foto]! [dos pliegos]).

En el protólogo de Chamissoa maximiliani Mart. ex Moq. el autor consigna "Mart.! herb. bras. N. 180" y posteriormente "v.s. in h. Mart. Mus. Vindob. et DC". Sohmer (1977) designó como lectotipo a un ejemplar depositado en G. Sin embargo, en este herbario se localizaron dos pliegos que no presentan anotaciones cruzadas que indiquen que pertenecen al mismo ejemplar. Por lo tanto, es necesario efectuar una lectotipificación de segundo paso, por lo que se designa a tal efecto al ejemplar G 00689321 por presentar mayor cantidad de estructuras reproductivas y porque el mismo forma parte del herbario de De Candolle, mientras que el ejemplar G 00429765 perteneció originalmente al herbario de Moricand.

Sohmer (1977) designó como lectotipo de Chamissoa maximiliani Moq. var. procumbens Seub. al ejemplar Riedel 702 (P). Sin embargo, en el protólogo del nombre de este taxón infraespecífico, el autor hace constar que dicho espécimen corresponde a la variedad típica, mientras que para la var. procumbens cita la colección "Riedel 699", sin consignar en qué herbario se halla depositada. En consecuencia, se rechaza la lectotipificación propuesta por Sohmer (1977) teniendo en cuenta el artículo 9.19(c) del ICN (Turland et al., 2018). Se han localizado dos ejemplares de la colección Riedel 699 depositados en M y P, designándose como lectotipo al segundo de ellos por constar de una planta rica en órganos vegetativos y reproductivos.

En el protólogo de Chamissoa maximiliani Moq. var. pubescens Chodat el autor menciona la colección "Hassler 467" sin consignar en 
qué herbario se halla depositada. En G fueron localizados dos ejemplares, cada uno de ellos montado en dos pliegos, sin presentar anotaciones cruzadas entre ambos pares. Se designa como lectotipo al ejemplar G 00103254, montado en dos pliegos que pertenecieron originalmente al herbario de Hassler, dado que su labelo presenta la anotación del nombre del taxón infraespecífico realizada con la grafía del autor.

24. Froelichia procera (Seub.) Pedersen, Darwiniana 14 (2-3): 448. 1967. 三 Froelichia lanata Moq. var. procera Seub., Fl. Bras. [Mart.] 5(1): 167. 1875. Tipo: Brasil. Minas Gerais, Uberava, I-1849, A. F. Regnell III 219 (Lectotipo [primer paso], S, designado por T. M. Pedersen, Darwiniana 14(2-3): 448. 1967; lectotipo [segundo paso], aquí designado, $\mathrm{S} \mathrm{n}{ }^{\circ} \mathrm{S} 07-12540$ [foto]!; isolectotipos, S n ${ }^{0}$ S07-12541 [foto]!, S n ${ }^{\circ}$ S0712542 [foto]!, US 00624260 [foto]!).

= Froelichia lanata Moq. var. paraguayensis Chodat, Bull. Herb. Boissier 7, App. I: 63. 1899. Tipo: Paraguay. Cordillera, Itacurubí, E. Hassler 1323 (Lectotipo, aquí designado, G 00103366 [foto]! [dos pliegos]; isolectotipos, G 00103367 [foto]!, K 000959895 [foto]!).

$=$ Froelichia lanata Moq. var. paraguayensis Chodat f. roseiflora Chodat, Bull. Herb. Boissier, sér. 2, 3: 354. 1903. Tipo: Paraguay. Cordillera, In regione collium, "Cerros de Tobaty", IX-1900, E. Hassler 6120 (Lectotipo, [primer paso], G, designado por T. M. Pedersen, Darwiniana 14(23): 449. 1967; lectotipo [segundo paso], aquí designado, G 00103375 [foto]!; isolectotipos, G 00103373 [foto]!, G 00103374 [foto]!, G 00103376 [foto]!, G 00103377 [foto]!, GH 00037060 [foto]!, K 000959894 [foto]!, MPU 016004 [foto]!, P 04926042 [foto]!, P 04926102 [foto]!, S no $07-$ 12539 [foto]!).

En el protólogo de Froelichia lanata Moq. var. procera Seub. el autor menciona varias colecciones sin especificar si corresponden a la variedad típica o a la var. procera. Pedersen (1967) citó como tipo al ejemplar Regnell III 219, depositado en S, designando de este modo al lectotipo de este nombre (Art. 7.11 Ej. 13 del ICN; Turland et al., 2018). Sin embargo, en este herbario se han localizado tres pliegos que no presentan anotaciones cruzadas que indiquen que pertenecen al mismo ejemplar. Por lo tanto, es necesario efectuar una lectotipificación de segundo paso, por lo que se designa a tal efecto al ejemplar S no S07-12540 por estar conformado por una planta con abundantes órganos vegetativos y reproductivos.

En el protólogo de Froelichia lanata Moq. var. paraguayensis Chodat el autor menciona la colección "Hassler 1323" sin consignar el herbario donde se halla depositada. Se localizaron tres ejemplares, dos en $\mathrm{G}$ y uno en $\mathrm{K}$, y no puede asegurarse que el autor haya usado uno solo de ellos. Se designa como lectotipo al ejemplar G 00103366, que se halla montado sobre dos pliegos que pertenecieron originalmente al herbario de Hassler, dado que su labelo presenta la anotación del nombre del taxón infraespecífico realizada con la grafía del autor.

En el protólogo de Froelichia lanata Moq. var. paraguayensis Chodat f. roseiflora Chodat el autor menciona la colección "Hassler 6120" sin consignar el herbario donde se halla depositada. Pedersen (1967) citó como tipo a un ejemplar depositado en $\mathrm{G}$, designando de este modo al lectotipo de este nombre (Art. $7.11 \mathrm{Ej} .13$ del ICN; Turland et $a l ., 2018)$. Sin embargo, en G se localizaron cinco pliegos que no presentan anotaciones cruzadas que indiquen que pertenecen al mismo ejemplar. Por lo tanto, es necesario efectuar una lectotipificación de segundo paso, por lo que se designa a tal efecto al ejemplar G 00103375 dado que su labelo presenta la anotación "Froelichia lanata Moq. var. paraguariensis Chod." realizada con la grafía del autor. Si bien este ejemplar no presenta la anotación del nombre completo del taxón, la misma situación se da en los restantes pliegos depositados en G, los cuales no fueron anotados por el autor.

25. Froelichia tomentosa (Mart.) Moq., Prodr. [De Candolle] 13(2): 421. 1849. 三 Oplotheca tomentosa Mart., Nov. Gen. Sp. Pl. 2: 48. 1826. Tipo: Probablemente Uruguay, "Brasilia", sin localidad consignada, F. Sellow s.n. (Lectotipo, aquí designado, K 000583135 [foto]!; isolectotipos, BM 000796349 [foto]! [el labelo consigna "Brazil"], F 0047606F [foto]! [el labelo consigna "Brazil"] [fragmento], P 00623757 [foto]!).

En el protólogo de Oplotheca tomentosa Mart. el autor menciona una colección realizada por Sellow en "Brasiliae Provincia Cisplatina" (uno de 
los antiguos nombres utilizados para designar a la actual República Oriental del Uruguay y a regiones del sudoeste del estado de Rio Grande do Sul de Brasil), sin consignar el herbario donde se halla depositada. Se localizaron cuatro ejemplares, de los cuales uno es un fragmento, que llevan anotado el nombre del basónimo o bien Froelichia tomentosa, cuyos labelos consignan "Brasilia" (K), "Brazil" (BM, F) y "Brasil. Merid.” (P), designándose como lectotipo al ejemplar K 000583135 por presentar una planta con hojas bien desarrolladas y varias inflorescencias.

26. Hebanthe erianthos (Poir.) Pedersen, Bonplandia 10: 101. 2000.

= Pfaffia paraguayensis Chodat, Bull. Soc. Bot. Genève 18: 286. 1927. Tipo: Paraguay. Caaguazú, Reg. fluminis Yhù, E. Hassler 9459 (Lectotipo [primer paso], G, designado por T. Borsch \& T. M. Pedersen, Sendtnera 4: 18. 1997; lectotipo [segundo paso], aquí designado, G 00103758 [foto]!; isolectotipos, G 001037755 [foto]!, G 001037756 [foto]!, G 001037757 [foto]! [dos pliegos], K 000196258 [foto]!).

= Pfaffia laurifolia Chodat, Bull. Soc. Bot. Genève 18: 287. 1927. Tipo: Paraguay. Amambay, in alta planitie, VII-1907/1908, E. Hassler 11280 (Lectotipo [primer paso], G, designado por T. Borsch \& T. M. Pedersen, Sendtnera 4: 18. 1997; lectotipo [segundo paso], aquí designado, G 00103761 [foto]! [dos pliegos]; isolectotipos, G 001037759 [foto]! [dos pliegos], G 001037760 [foto]! [tres pliegos], G 001037762 [foto]!, K 000196257 [foto]!, M 0241558 [foto]! [fragmento ex B], MPU 016068 [foto]!).

En el protólogo de Pfaffia paraguayensis Chodat el autor menciona la colección "Hassler 9459" sin consignar el herbario donde se halla depositada. Borsch \& Pedersen (1997) citaron como holotipo a un ejemplar depositado en G; sin embargo, en este herbario se localizaron cuatro duplicados que no presentan anotaciones cruzadas que indiquen que pertenecen al mismo ejemplar y no puede asegurarse que el autor haya usado uno solo de ellos. Según el Art. 9.10 del ICN (Turland et al., 2018) la indicación de holotipo por Borsch y Pedersen (1997) puede considerarse un error factible de ser corregido, tomándose como lectotipo (McNeill, 2014; Prado et al., 2015). Sin embargo, según el
Art. 40, Nota 1 del ICN (Turland et al., 2018; cfr. McNeill, 2014), como en el protólogo del nombre de la especie no se explicitó el herbario donde estaba depositado el ejemplar y se han localizado duplicados en dos instituciones, estos deben ser considerados sintipos. Ramella (2016) consideró como holotipo de la especie a G 00103758 , mientras que trató como isotipos a los restantes ejemplares examinados por él y que se hallan depositados en el mismo herbario. La indicación de holotipo de Ramella (2016) no puede considerarse un error factible de ser corregido a lectotipo, puesto que desde el $1^{\circ}$ de enero de 2001 para efectuar la designación de un lectotipo de un nombre de especie o taxón infraespecífico es necesario consignar dicho término seguido de las palabras "aquí designado" en latín o su equivalente en un idioma moderno (Art. 7.11 y Art. 9.23 del ICN; Turland et al., 2018). En consecuencia, se procedió aquí a efectuar la lectotipificación de segundo paso, por lo que se designa a tal efecto al ejemplar G 00103758, dado que en su labelo presenta la anotación "Type / Pfaffia paraguayensis Chodat / 1926 " realizada por el propio autor.

En el protólogo de Pfaffia laurifolia Chodat el autor menciona la colección "Hassler 11280" sin consignar el herbario donde se halla depositada. Borsch \& Pedersen (1997) citaron como holotipo a un ejemplar depositado en $G$; sin embargo, se localizaron varios duplicados en diferentes herbarios y no puede asegurarse que el autor haya usado uno solo de ellos. Según el Art. 9.10 del ICN (Turland et al., 2018) esta indicación puede considerarse un error factible de ser corregido, tomándose como lectotipo (McNeill, 2014; Prado et al., 2015). Ramella (2016) consideró como holotipo de la especie a G 001037761, mientras que trató como isotipos a los restantes ejemplares mencionados por él. Sin embargo, según el Art. 40, Nota 1 del ICN (Turland et al., 2018; cfr. McNeill, 2014), como en el protólogo del nombre de la especie no se explicitó el herbario donde estaba depositado el ejemplar y se han localizado duplicados en varias instituciones, estos deben ser considerados sintipos; la indicación de holotipo de Ramella (2016) no puede considerarse un error factible de ser corregido a lectotipo, debido a la fecha de publicación (Art. 7.11 y Art. 9.23 del ICN; Turland et al., 2018). En consecuencia, se procedió aquí a efectuar la lectotipificación de segundo 
paso, por lo que se designa a tal efecto al ejemplar G 00103761, dado que en su labelo presenta la anotación "Pfaffia laurifolia Chod. 1926" realizada por el propio autor. Este espécimen se halla montado sobre dos pliegos que originalmente pertenecieron al herbario de Barbey-Boissier.

27. Hebanthe occidentalis (R. E. Fr.) T. Borsch \& Pedersen, Sendtnera 4: 21. 1997. 三 Pfaffia occidentalis R. E. Fr., Ark. Bot. 16(12): 8. 1920. Tipo: Argentina. Jujuy, Quinta pr.[ope] Laguna de la Brea, ad. Sierra Santa Bárbara, 8-VIII-1901, R. E. Fries 448 (Lectotipo [primer paso], S, designado por T. Borsch \& T. M. Pedersen, Sendtnera 4: 21. 1997; lectotipo [segundo paso], aquí designado, S $\mathrm{n}^{\circ}$ S07-12581 [foto]!; isolectotipos, P 00610559 [foto]!, S no S-R-4415 [foto]!, S n ${ }^{\circ}$ S-07-12582 [foto]!, US 00102743 [foto]!).

$=$ Pfaffia occidentalis R. E. Fr. var. densiflora R. E. Fr., Ark. Bot. 16(12): 9. 1920. Tipo: Argentina. Jujuy, Quinta pr.[ope] Laguna de la Brea, 8-VII1901, R. E. Fries 443 (Lectotipo [primer paso], $\mathrm{S}$, designado por T. Borsch \& T. M. Pedersen, Sendtnera 4: 21. 1997; lectotipo [segundo paso], aquí designado, $\mathrm{S} \mathrm{n}^{\circ} \mathrm{S} 07-12585$ [foto]!; isolectotipos, $\mathrm{S} \mathrm{n}^{\circ}$ S-R-4416 [foto]!, $\mathrm{S} \mathrm{n}^{\mathrm{o}} \mathrm{S} 07-$ 12583 [foto]!, US 00102744 [foto]!).

= Pfaffia brachiata Chodat var. grandiflora O. Stützer, Repert. Spec. Nov. Regni Veg. Beih. 88: 8. 1935. Tipo:Argentina. Jujuy, Quinta pr.[ope] Laguna de la Brea ad. Sierra Santa Bárbara, 22-VII-1901, R. E. Fries 386 (Lectotipo [primer paso], S, designado por T. Borsch \& T. M. Pedersen, Sendtnera 4: 21. 1997; lectotipo [segundo paso], aquí designado, $\mathrm{S}$ $\mathrm{n}^{\circ} \mathrm{S} 17-54114$ [foto]!; isolectotipos, $\mathrm{S} \mathrm{n}^{\circ} \mathrm{S} 17-54111$ [foto]!, S n ${ }^{\circ}$ S06-5055 [foto]!).

En el protólogo de Pfaffia occidentalis R. E. Fr. el autor menciona la colección "Fries 448" sin consignar el herbario donde se halla depositada. Borsch \& Pedersen (1997) citaron como holotipo a un ejemplar depositado en $\mathrm{S}$; sin embargo, se localizaron varios duplicados en diferentes herbarios. Según el Art. 9.10 del ICN (Turland et al., 2018) esta indicación puede considerarse un error factible de ser corregido, tomándose como lectotipo (McNeill, 2014; Prado et al., 2015). En $\mathrm{S}$ se localizaron tres duplicados que no presentan anotaciones cruzadas que indiquen que pertenecen al mismo ejemplar. Por lo tanto, es necesario efectuar una lectotipificación de segundo paso, por lo que se designa a tal efecto al ejemplar $\mathrm{S} \mathrm{n}^{\circ}$ S07-12581 por tratarse de una rama con abundantes hojas e inflorescencias.

En el protólogo de Pfaffia occidentalis R. E. Fr. var. densiflora R. E. Fr. el autor menciona dos colecciones que corresponden a sintipos, "Fries 443 " y "Lorentz \& Hieronymus 250", sin consignar el herbario donde se hallan depositadas. Borsch \& Pedersen (1997) citaron como holotipo a la primera de ellas depositada en S; según el Art. 9.10 del ICN (Turland et al., 2018) esta indicación puede considerarse un error factible de ser corregido, tomándose como lectotipo (McNeill, 2014; Prado et al., 2015). Sin embargo, en dicho herbario se localizaron tres ejemplares que no presentan anotaciones cruzadas que indiquen que pertenecen al mismo ejemplar. Por lo tanto, es necesario efectuar una lectotipificación de segundo paso, por lo que se designa a tal efecto al ejemplar $\mathrm{S} \mathrm{n}^{\circ} \mathrm{S} 07$ 12585 por presentar tanto estructuras vegetativas como reproductivas.

En el protólogo de Pfaffia brachiata Chodat var. grandiflora O. Stützer la autora menciona cuatro colecciones que corresponden a sintipos, "Malme II 2133", "Pflanz 4076", "Fries 386" y "Fries 386a", sin consignar el herbario donde se hallan depositadas. Borsch \& Pedersen (1997) designaron como lectotipo a la colección Fries 386 depositada en S. Sin embargo, en este herbario se localizaron tres duplicados de la misma -uno de ellos conservado en un frasco con alcohol- que no presentan anotaciones cruzadas que indiquen que pertenecen al mismo ejemplar. Por lo tanto, es necesario efectuar una lectotipificación de segundo paso, por lo que se designa a tal efecto al ejemplar $\mathrm{S} \mathrm{n}^{\mathrm{o}} \mathrm{S} 17-54114$ por tratarse de una rama con abundantes hojas e inflorescencias.

28. Pfaffia glomerata (Spreng.) Pedersen, Darwiniana 14: 450. 1967.

= Sertuernera luzuliflora Mart., Nov. Gen. Sp. Pl. [Martius] 2(1): 39. 1826. Tipo: Probablemente Uruguay, "Brasil. meridionalis", sin localidad consignada, F. Sellow s.n. (Lectotipo, aquí designado, HAL 0010432 [foto]!).

= Pfaffia divergens O. Stützer, Repert. Spec. Nov. Regni Veg. Beih. 88: 31. 1935. Tipo: Argentina. Salta, Rosario de Lerma, Campo Quijano, 1600 m, 16-I-1929, S. Venturi 8068 (Lectotipo, aquí 


\section{N. D. Bayón y D. A. Giuliano - Lectotipificaciones en Amaranthaceae}

designado, US 00102738 [foto]!; isolectotipos, F $0047633 \mathrm{~F}$ [foto]!, GH 00037129 [foto]!, CAS 0003902 [foto]!).

= Pfaffia luzuliflora (Mart.) D. Dietr. f. gracilis O. Stützer, Repert. Spec. Nov. Regni Veg. Beih. 88: 34. 1935. Tipo: Argentina. Buenos Aires, Los Talas, 18-IV-1934, A. L. Cabrera 2923 (Lectotipo, aquí designado, M 0241561 [foto]!; isolectotipo, $\mathrm{S} \mathrm{n}^{\circ}$ 07-12564 [foto]!).

En el protólogo de Sertuernera luzuliflora Mart. el autor menciona una colección realizada por Sellow procedente de la "Provincia Cisplatina" (uno de los nombres para designar al territorio de la actual República Oriental del Uruguay y áreas del sudoeste del estado de Rio Grande do Sul, Brasil), sin consignar en qué herbario se halla depositada. No se ha podido localizar ningún espécimen en $\mathrm{M}$, ni en BR, siendo este último el herbario donde actualmente se halla la colección privada de Martius (Stafleu \& Cowan, 1981). Sin embargo, se ha localizado un ejemplar colectado por Sellow depositado en HAL cuyo labelo consigna "Brasil. meridionalis" y presenta la anotación "Sertürnera luzulaeflora, Mart." realizada por Schlechtendal (Pedersen, 1967), el cual es aquí designado como lectotipo.

En el protólogo de Pfaffia divergens O. Stützer la autora menciona la colección "Venturi 8068", indicando que se halla depositada en GH, MO y US. Se designa aquí como lectotipo al ejemplar US 00102738 por presentar abundantes estructuras vegetativas y reproductivas.

En el protólogo de Pfaffia luzuliflora (Mart.) D. Dietr. f. gracilis O. Stützer la autora menciona seis colecciones que corresponden a sintipos realizadas por diferentes colectores en Argentina, Bolivia, Brasil y Uruguay: "Rusby 1517" (NY 02461050 [foto]!, NY 02474401 [foto]!), "Werdermann 2163" (S no 07-12563 [foto]!), "Gilbert 14" (no localizado), "Herter 10035b" (no localizado), “Cabrera 2923” y "Quiroga 7707" (S n 07-12565 [foto]!). Se designa como lectotipo al ejemplar Cabrera 2923 depositado en M por presentar abundantes estructuras vegetativas y reproductivas. Cabe aclarar que en LP existe un pliego (LP003664) cuyo labelo coincide en un todo con los datos consignados en el protólogo; sin embargo, sobre el mismo se halla montada una planta que se corresponde con Alternanthera paronychioides A.
St.-Hil. subsp. chacoensis (Morong ex Morong \& Britton) Pedersen.

29. Pfaffia gnaphaloides (L. f.) Mart., Beitr. Amarantac.: 104. 1825. $\equiv$ Celosia gnaphaloides L. f., Suppl. Pl.: 161. 1782. Tipo: Uruguay. Montevideo, P. Commerson s.n. (Lectotipo [primer paso], MPU, designado por T. M. Pedersen, Darwiniana 14 (2-3): 454. 1967; lectotipo [segundo paso], aquí designado, MPU 015872 [foto]!; isolectotipos, LINN no 425.14 [foto]! [fragmento], MPU 015873 [foto]!).

En el protólogo de Celosia gnaphaloides L. f. el autor menciona "Habitat in Monte Video in Brasilia. Thouin.”. En rigor la colección fue realizada por Commerson y depositada en el herbario de Thouin, el cual posteriormente fue incorporado al herbario de Cambessèdes que actualmente se halla en MPU, tal como es mencionado por Pedersen (1967). Este autor citó como tipo un ejemplar depositado en dicho herbario, designando de este modo al lectotipo de este nombre (Art. 7.11 Ej. 13 del ICN; Turland et al., 2018); sin embargo, allí se localizaron dos pliegos que no presentan anotaciones cruzadas que indiquen que pertenecen al mismo ejemplar. Por lo tanto, es necesario efectuar una lectotipificación de segundo paso, por lo que se designa a tal efecto al ejemplar MPU 015872 por presentar dos plantas completas acompañadas por fragmentos.

30. Pfaffia helichrysoides (Moq.) Kuntze, Revis. Gen. Pl. 2: 544. 1891. EGomphrena helichrysoides Moq., Prodr. [De Candolle] 13(2): 391. 1849. Tipo: Brasil. Minas Gerais, P. Claussen 45 (Lectotipo, aquí designado, G-DC G 006894381 [foto]!; isolectotipo, G 00410002 [foto]!).

= Pfaffia gnaphaloides (L. f.) Mart. f. subferruginea O. Stützer, Repert. Spec. Nov. Regni Veg. Beih. 88: 26. 1935. Tipo: Brasil. Minas Gerais, 1845, Widgren s.n. (Lectotipo, aquí designado, $\mathrm{P}$ 04559167 [foto]!; isolectotipos, B, M, no vistos).

En el protólogo de Gomphrena helichrysoides Moq. el autor cita "Clauss.! pl. exs. n. 25 aut 45", aclarando posteriormente "v.s. in h. DC.". En el herbario G-DC sólo se ha localizado el ejemplar Claussen 45, el cual consta de un pequeño fragmento con una inflorescencia. Por otra parte en $\mathrm{G}$, procedente del Herbario de Delessert se 
encuentra el ejemplar Claussen 25 (en cuyo labelo también figura el número 56), como así también un duplicado de Claussen 45 procedente del herbario de Moricand. Se designa como lectotipo al ejemplar Claussen 45 (G-DC G 006894381) depositado en el herbario de De Candolle, dado que este fue el consignado en el protólogo.

En el protólogo de Pfaffia gnaphaloides (L. f.) Mart. f. subferruginea O. Stützer la autora menciona dos colecciones que corresponden a sintipos, "Riedel 2328" y "Widgren s.n.”, indicando que se hallan depositados en los herbarios B, M y P. Después de examinar ambas colecciones, se designa como lectotipo al ejemplar Widgren s.n. (P 04559167) por presentar varias plantas con abundantes hojas e inflorescencias; los duplicados de este ejemplar mencionados por la autora no han sido localizados.

\section{Agradecimientos}

Los autores agradecen a Christian Zanotti y Diego Gutiérrez por la lectura crítica del manuscrito y sus valiosas contribuciones que ayudaron a mejorar el mismo. Asimismo, agradecemos a los curadores de los herbarios B, C, G, GOET, K y S que han contribuido con el envío de imágenes y comentarios, sin los cuales no habría sido posible realizar este trabajo, especialmente a Laurent Gautier.

\section{Bibliografía}

BORSCH, T. 2008. Amaranthaceae. En ZULOAGA, F. O., O. MORRONE \& M. J. BELGRANO (eds.). Catálogo de las Plantas Vasculares del Cono Sur: Argentina, Sur de Brasil (Paraná, Santa Catarina y Rio Grande do Sul), Chile, Paraguay y Uruguay. Monogr. Syst. Bot. Missouri Bot. Gard. 107: 10111043.

BORSCH, T. \& T. M. PEDERSEN. 1997. Restoring the generic rank of Hebanthe Martius (Amaranthaceae). Sendtnera 4: 13-31.

CHODAT, R. \& L. REHFOUS. 1927. La végétation du Paraguay 14. Amarantacées. Bull. Soc. Bot. Genève, sér. 2, 18: 246-294.

GREUTER, W. \& R. RANKIN RODRÍGUEZ. 2012. Código Internacional de Nomenclatura para Algas, Hongos y Plantas (Código de Melbourne).
Traducción al español de la versión oficial en inglés autorizada por la International Association for Plant Taxonomy. Real Jardín Botánico, Madrid y Editorial CSIC, Madrid.

MCNEILL, J. 2014 Holotype specimens and type citations: General issues. Taxon 63: 1112-1113.

MEARS, J. A. 1977. The nomenclature and type collections of the widespread taxa of Alternanthera (Amaranthaceae). Proc. Acad. Nat. Philadelphia 129: 1-21.

MEARS, J.A. 1982. A summary of Blutaparon Rafinesque including species early known as Philoxerus R. Brown (Amaranthaceae). Taxon 31: 111-117.

MELVILLE, R. 1958. Notes on Alternanthera. Kew Bull. 13: 171-175.

PEDERSEN, T. M. 1967. Studies in South American Amaranthaceae. Darwiniana 14: 430-462.

PEDERSEN, T. M. 1997. Studies in South American Amaranthaceae IV. Adansonia, sér. 3, 19: 217-251.

PEDERSEN, T. M. 2000. Studies in South American Amaranthaceae V. Bonplandia 10: 83-112.

PRADO, J., R. J. HIRAI \& R. C. MORAN. 2015. (046-048) Proposals concerning inadvertent lectotypifications (and neotypifications). Taxon 64: 651.

RAMELLA, L. 2016. Nomenclatura, tipificaciones y sinónimos nuevos en la familia Amaranthaceae de la Flora del Paraguay. Candollea 71: 311-326.

SOHMER, S. H. 1977. A revision of Chamissoa (Amaranthaceae). Bull. Torrey Bot. Club 104: 111126.

STAFLEU F. A. \& R. S. COWAN. 1976. Taxonomic literature, Vol. 1: A-G. 2da ed. Bohn, Scheltema \& Holkema, Utrecht.

STAFLEU F. A. \& R. S. COWAN. 1981. Taxonomic literature, Vol. 3: Lh-O. 2da ed. Bohn, Scheltema \& Holkema, Utrecht.

THIERS, B. 2018. Index Herbariorum: A global directory of public herbaria and associated staff. New York Botanical Garden's Virtual Herbarium. Disponible en http://sweetgum.nybg.org/ih/: [Acceso: 21 Marzo 2018].

TURLAND, N. J., J. H. WIERSEMA, F. R. BARRIE, W. GREUTER, D. L. HAWKSWORTH, P. S. HERENDEEN, S. KNAPP, W. H. KUSBER, D. Z. LI, K. MARHOLD, T. W. MAY, J. MCNEILL, A. M. MONRO, J. PRADO, M. J. PRICE \& G. F. SMITH (eds.). 2018. International Code of Nomenclature for algae, fungi, and plants (Shenzhen Code). Regnum Veg. 159. Koeltz Botanical Books, Glashütten.

Recibido el 29 de marzo de 2018, aceptado el 14 de agosto de 2018. Editora: Carolina I. Calviño. 